\title{
Electrochemical Characterization of a Self-Assembled
}

\section{Polyelectrolyte Film}

\author{
T.H. Silva, S.V.P. Barreira, C. Moura, F. Silva * \\ LEQA - Laboratório de Electroquímica e Química AnalíticaCIQ - L4, Departamento de \\ Química, Faculdade de Ciências do Porto \\ Rua do Campo Alegre, 687, 4169-007 PORTO, Portugal \\ Received 19 February 2003; accepted 15 May 2003
}

\begin{abstract}
Polyelectrolyte thin films constructed using the method proposed by Decher and coworkers are studied using several electrochemical techniques, such as cyclic voltammetry and linear sweep voltammetry with rotative disc electrode. The main goal of this work is to evaluate the influence of the number of layers and the charge of the external layer in thin film permeability. These films seem to have electrochemical properties strongly influenced by deposition conditions. It's shown that the increased number of layers lowers film permeability.
\end{abstract}

Keywords: polyelectrolytes, thin films, self-assembly, surface, electrochemistry.

\section{Introduction}

In the 90's, Decher and co-workers proposed a new technique of thin film construction, based on self-assembling of polyelectrolytes of opposite charge, ruled by electrostatic forces [1]. This technique allows the build-up of multilayers in a way largely independent on the nature, size and topology of the substrate, and without restriction to the need of covalent chemistry (complete reactions) provided that the surface of the substrate is adequately modified $[1,2]$.

\footnotetext{
* Corresponding author. E-mail: thsilva@fc.up.pt
} 
Several experimental variables control the build-up of these films, but the concentration of salt in the deposition solution seems to have the strongest influence, when compared with salt composition, molecular weight, polymer concentration and deposition time $[3,4]$.

Reproducible preparation of films is dependent on the substrate's surface charge density [5]. The first step of polyelectrolyte film construction is the modification of the surface. This modification is performed normally with charged species covalently bonded to the substrate in a way that gives constant surface charge. If the substrate has constant surface charge, construction of equivalent films in different substrates is possible.

The construction of a polyelectrolyte film by self-assembling is very simple and easy but, probably, the major advantage of this layer-by-layer adsorption is that many different materials can be incorporated in multilayer films, having an important contribution to the several applications of these films, from which it can be highlighted separation [6] and sensor devices [7-13].

The assembly of a polyelectrolyte film on an electrode surface yields a positively or negatively charged interface, exposed to the electrolyte solution, being, in practice, a modified electrode. These modified electrodes may be used to control electrochemical transformations at the electrode surface [14]. If there are no electroactive groups within the polyelectrolyte film, this film is a barrier to the electronic charge transfer, with its resistance increasing with film thickness. However, film permeability, due to pores or pinholes, allows the diffusion of electroactive species, and thus allowing electrochemical reactions, controlled by the interaction between film and species [14]. The diffusion of small ions must also be possible to attain electroneutrality, which implies swelling [15].

Dealing with different polyelectrolytes, film thickness (number of layers) and charge signal of the external layer (which influence all the film charge), achievement of selective electrochemical responses to a mixture of differently charged electroactive species is expected.

The main objective of this work is to study the influence of charge signal of the external layer, number of layers and deposition conditions on films permeability. 


\section{Experimental}

\section{Materials}

Cysteamine (Fluka), poly(sodium 4-styrenesulfonate) (PSS) (MW=70000) (Aldrich), poly(allylamine hydrochloride) (PAH) (MW=15000) (Aldrich), $\mathrm{Ba}\left(\mathrm{ClO}_{4}\right)_{2}$ (Pronalys* AR) and potassium hexacyanoferrate (II) trihydrate (Fluka) were all used without further purification. Ultra pure water $\left(18 \mathrm{M} \Omega . \mathrm{cm}^{-1}\right.$, Millipore) was used in all experiments and in all cleaning procedures.

Gold disc electrodes ( $2 \mathrm{~mm}$ diameter) connected to a rotative system (Radiometer) were used for electrochemical measurements.

\section{Film Preparation}

Prior to film preparation, gold disc electrodes were cleaned according to the following technique: they were polished in a polishing cloth (Buehler) and rinsed in water. They were then cleaned by cycling between the potentials -0.3 and 1.5 $\mathrm{V}$ versus $\mathrm{Ag} / \mathrm{AgCl}$ in $0.1 \mathrm{M} \mathrm{HClO}_{4}$ solution at a scan rate of $100 \mathrm{mV} \mathrm{s}^{-1}$ until reproducible scans were recorded (approximately $1 \mathrm{~h}$ ). Finally, the electrodes were rinsed with water and ethanol.

The clean electrodes were immersed in a $3 \mathrm{mM}$ cysteamine ethanolic solution, overnight for approximately 14 to 16 hours. They were then rinsed with ethanol, followed by water. The first polyelectrolyte layer was deposited onto a cysteamine-modified electrode from aqueous $0.1 \mathrm{M}$ acetate buffer solution, $\mathrm{pH}=$ 4.5, containing $1 \mathrm{mg} \mathrm{mL}^{-1}$ of PSS, for $20 \mathrm{~min}$ and then rinsed with water for 1 min. The next layer was deposited onto the PSS layer from aqueous $0.1 \mathrm{M}$ acetate buffer solution, $\mathrm{pH}=4.5$, containing $1 \mathrm{mg} \mathrm{mL}^{-1}$ of $\mathrm{PAH}$, for $20 \mathrm{~min}$ and then rinsed with water for $1 \mathrm{~min}$. This procedure was repeated to produce the desired number of polyelectrolyte layers and contrasts with the procedure described in reference 16 where two different concentrations of $\mathrm{H}_{2} \mathrm{SO}_{4}$ were employed to produce the initial positive layer. Fig. 1 shows a scheme of the building up of the film. 


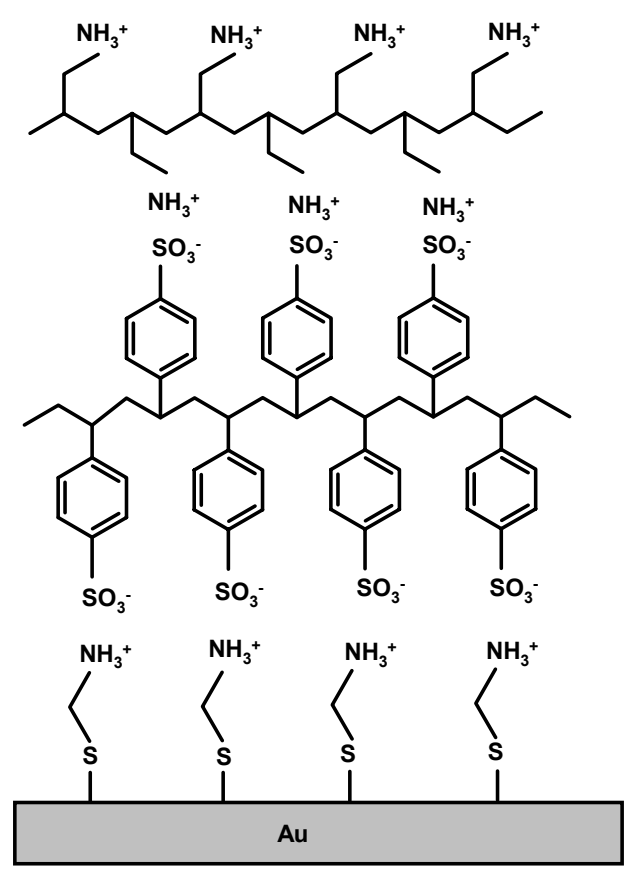

Figure 1. Scheme of a film with general formula $\mathrm{Au}+$ cysteamine $+(\mathrm{PSS}+\mathrm{PAH})$.

\section{Electrochemical Measurements}

All electrochemical experiments were performed in a three-electrode cell at room temperature $\left(\approx 20^{\circ} \mathrm{C}\right)$ : modified gold disc as working electrode, a platinum net as counter electrode and an $\mathrm{Ag} / \mathrm{AgCl} / \mathrm{KCl} 3 \mathrm{M}$ reference electrode, connected to the working volume with a Luggin capillary, against which all potentials are reported. The cell was enclosed in a grounded Faraday cage.

Cyclic and linear sweep voltammetry measurements were performed with the electrochemical cell filled with $0.1 \mathrm{M} \mathrm{Ba}\left(\mathrm{ClO}_{4}\right)_{2}+1 \mathrm{mM} \mathrm{K}_{4}\left[\mathrm{Fe}(\mathrm{CN})_{6}\right]$, using an Autolab PSTAT 10 potentiostat, between -0.2 and $0.6 \mathrm{~V}$, using several sweep rates $\left(10-500 \mathrm{mV} \mathrm{s}^{-1}\right)$. The rotative disc electrode experiments were carried out at several rotation rates, between 100 and $4900 \mathrm{rpm}$.

Solutions filling the electrochemical cell were purged with nitrogen for $10 \mathrm{~min}$ before each measurement, and the cell was kept under flowing nitrogen for the duration of the experiment. 


\section{Results and discussion}

The film permeability to ions was firstly evaluated using an electrochemical probe, $\left[\mathrm{Fe}(\mathrm{CN})_{6}\right]^{3-/ 4-}$, and cyclic voltammetry. Two different effects can be understood from the cyclic voltammograms obtained (Fig. 2): first, the peak current decreases with increasing number of layers and after the voltammograms become a wave, eventually disappearing; second, changing the sign of the external layer from positive (even-layer film) to negative (odd-layer film) dramatic decrease in current intensity is observed.

The peak separation is given in Table 1. The half wave potential remains practically constant but the peak separation increases from an initial value of 70 $\mathrm{mV}$. These values are similar to those reported by Han et al. [16] with similar multilayer films.

These results point to the presence of two main effects on the film permeability: film thickness and external charge sign.

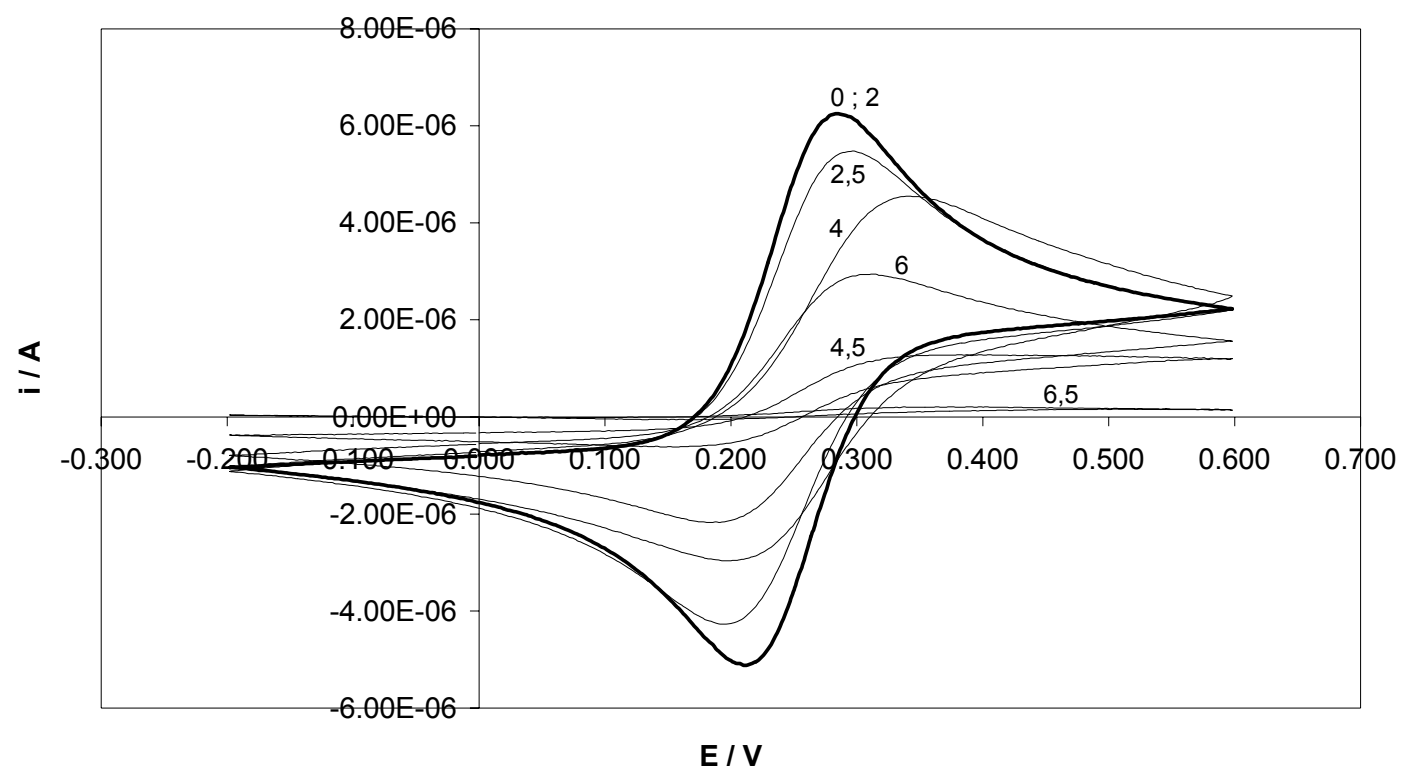

Figure 2. Cyclic voltammograms of film modified electrodes $\mathrm{Au}+$ cysteamine $+(\mathrm{PSS}+\mathrm{PAH})_{\mathrm{n}}$. Supporting electrolyte: $0.1 \mathrm{M} \mathrm{Ba}\left(\mathrm{ClO}_{4}\right)_{2}$, with $1 \mathrm{mM}$ $\left[\mathrm{Fe}(\mathrm{CN})_{6}\right]^{4-}$. Sweep rate: $100 \mathrm{mV} \mathrm{s}^{-1}$. The numbers indicate the $\mathrm{n}$ value in $\mathrm{Au}+$ cysteamine $+(\mathrm{PSS}+\mathrm{PAH})_{\mathrm{n}}$. 
The understanding of the process occurring at the electrode film interface during the oxidation/reduction of ferrocyanide probe may be helped with experiments using rotative electrode.

Table 1. Values of anodic and cathodic peak currents $\left(\mathrm{i}_{\mathrm{pa}}, \mathrm{i}_{\mathrm{pc}}\right)$ and potentials $\left(\mathrm{E}_{\mathrm{pa}}, \mathrm{E}_{\mathrm{pc}}\right)$ of the voltammograms in Fig. 2. The voltammogram for $n=6.5$ does not have peaks.

\begin{tabular}{ccccccc}
\hline $\mathrm{N}$ & $\mathrm{E}_{\mathrm{pa}} / \mathrm{V}$ & $\mathrm{i}_{\mathrm{pa}} / \mathrm{A}$ & $\mathrm{E}_{\mathrm{pc}} / \mathrm{V}$ & $\mathrm{i}_{\mathrm{pc}} / \mathrm{A}$ & $\mathrm{E}_{1 / 2} / \mathrm{V}$ & $\Delta \mathrm{E}_{\mathrm{p}} / \mathrm{V}$ \\
\hline 0 & 0.283 & $6.71 \times 10^{-6}$ & 0.210 & $-6.46 \times 10^{-6}$ & 0.246 & 0.073 \\
2 & 0.283 & $6.71 \times 10^{-6}$ & 0.210 & $-6.46 \times 10^{-6}$ & 0.246 & 0.073 \\
2.5 & 0.295 & $5.84 \times 10^{-6}$ & 0.195 & $-5.30 \times 10^{-6}$ & 0.246 & 0.100 \\
$4 *$ & 0.342 & $4.80 \times 10^{-6}$ & 0.198 & $-3.37 \times 10^{-6}$ & 0.270 & 0.144 \\
4.5 & 0.381 & $1.50 \times 10^{-6}$ & 0.159 & $-1.14 \times 10^{-6}$ & 0.270 & 0.122 \\
6 & 0.305 & $3.17 \times 10^{-6}$ & 0.190 & $-2.83 \times 10^{-6}$ & 0.248 & 0.115 \\
\hline
\end{tabular}

$\left(^{*}\right)$ This film gave unexpected results and no explanation can be given at this moment.

Table 2. Values of limiting current $\left(i_{L}\right)$ and half wave potential $\left(E_{1 / 2}\right)$ of the voltammograms in Fig. 3. For those in which doesn't exist limiting current, $i_{L}$ is the current at $\mathrm{E}=600 \mathrm{mV}$.

\begin{tabular}{ccc}
\hline $\mathrm{n}$ & $\mathrm{i}_{\mathrm{L}} / \mathrm{A}$ & $\mathrm{E}_{1 / 2} / \mathrm{V}$ \\
\hline 0 & $1.38 \times 10^{-5}$ & 0.253 \\
2 & $1.38 \times 10^{-5}$ & 0.253 \\
2.5 & $1.26 \times 10^{-5}$ & 0.253 \\
4 & $9.62 \times 10^{-6}$ & 0.267 \\
4.5 & $2.48 \times 10^{-6}$ & 0.257 \\
6 & $6.76 \times 10^{-6}$ & 0.255 \\
6.5 & $2.21 \times 10^{-7}$ & 0.244 \\
\hline
\end{tabular}

Linear scan voltammograms for bare and film modified electrodes are depicted in Fig. 3, showing the classical S-shape for defined hydrodynamic conditions of a rotating disc electrode [17]. The corresponding values of limiting current $\left(i_{L}\right)$ and half wave potential $\left(\mathrm{E}_{1 / 2}\right)$ are presented in Table 2. 


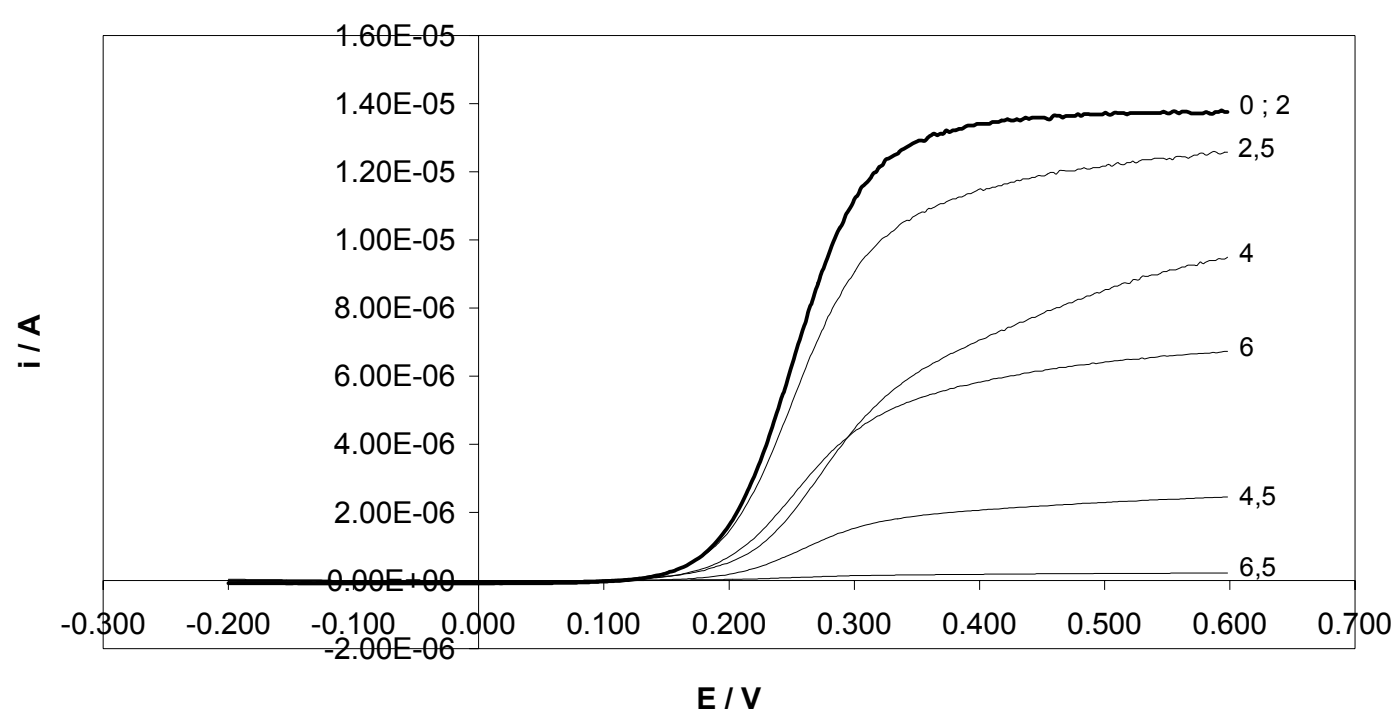

Figure 3. Linear scan voltammograms of film modified rotating disk electrodes $\mathrm{Au}+$ cysteamine $+(\mathrm{PSS}+\mathrm{PAH})_{\mathrm{n}}$. Supporting electrolyte: $0.1 \mathrm{M} \mathrm{Ba}\left(\mathrm{ClO}_{4}\right)_{2}$, with $1 \mathrm{mM}$ $\left[\mathrm{Fe}(\mathrm{CN})_{6}\right]^{4-}$. Sweep rate: $10 \mathrm{mV} \mathrm{s}^{-1}$; rotation rate: $900 \mathrm{rad} \mathrm{s}^{-1}$. The numbers indicate the $\mathrm{n}$ value in $\mathrm{Au}+$ cysteamine $+(\mathrm{PSS}+\mathrm{PAH})_{\mathrm{n}}$.

These results agree with those obtained with cyclic voltammetry and with others obtained by Farhat et al. [18]. A general decrease of the limiting current is observed due to the increasing number of layers, which seems to represent an increasing resistance to the electrochemical reaction. Nevertheless this is not the only effect, since the current for 9 layers is lower than for 12 layers. This can be due to the change of the external charge, changing the electrostatic interaction between film and probe ion from repulsive (nine layers) to attractive (twelve layers), which may have a stronger influence in the limiting current that the increased number of layers.

The transition of the cyclic voltammograms from peak shaped to plateau shaped with increasing number of layers suggests a transition between two different mass transport processes: from semi-infinite linear diffusion to convergent diffusion, possibly at an array of micro-holes.

A modified electrode undergoes some restrictions to the current due to resistance to electron transfer (slow redox kinetics) at the electrode/film interface or to smaller mass transfer through the film. The resistance to electron transfer can be overcome by increasing potential, so that the final limiting current is the same in 
the modified and bare electrode, but the potential of the oxidation wave is shifted. With lower mass transfer, lower limiting currents are obtained, but the potential is the same [18].

For an uncoated electrode of area $A\left(\mathrm{~cm}^{2}\right)$, rotating at angular velocity $w\left(\mathrm{rad} \mathrm{s}^{-1}\right)$, the limiting current $i_{l e v}$ is given by the Levich equation $[17,19]$ :

$$
i_{l e v}=0.620 n F A D^{2 / 3} w^{1 / 2} v^{-1 / 6} C_{S}
$$

where $n$ is the number of electrons transferred, $F$ is the Faraday's constant (96 $485 \mathrm{C} \mathrm{mol}^{-1}$ ), $D$ is the solution diffusion coefficient of the electroactive species $\left(\mathrm{cm}^{2} \mathrm{~s}^{-1}\right), v$ is the kinematic viscosity of the electrolyte $\left(\approx 0.01 \mathrm{~cm}^{2} \mathrm{~s}^{-1}\right.$ for dilute aqueous solution) and $C_{S}$ is the solution concentration $\left(\mathrm{mol} . \mathrm{cm}^{-3}\right)$. As seen in eq. $1, i_{l e v}$ is proportional to the square root of the rotation rate, and a plot of these parameters $\left(i_{l e v}\right.$ vs. $w^{1 / 2}-$ Levich plot) should be linear.

For a modified rotating disc electrode, there is a film between the solution and electrode surface, being crucial to understand what type of permeation occurs in it. Savéant [20] had considered two possibilities: membrane permeation and pinhole permeation, as shown in Fig. 4.

(a)

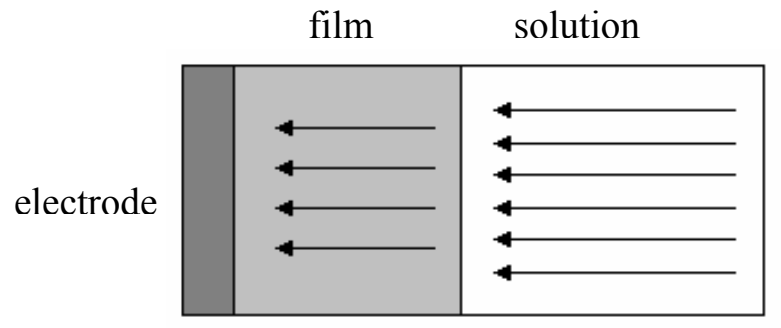

(b)

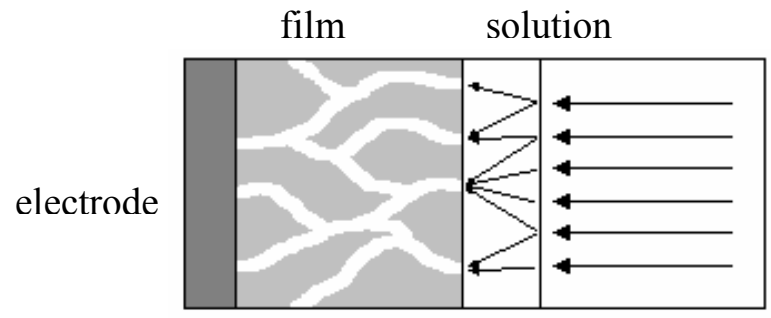

Figure 4. Schemes of membrane (a) and pinhole (b) permeation through the film, from the solution to electrode surface.

A model based on membrane permeation assumes a polyelectrolyte film as a viscous, concentrated polyelectrolyte solution bonded to the electrode, in which electroactive species penetrate and diffuse. This model was applied initially by Ikeda et al. [21], and the limiting current $i_{\ell}$ was found to be described by eq. (2): 


$$
\frac{1}{i_{\ell}}=\frac{1}{n F A D_{F} P C_{S} / d}+\frac{1}{0.620 n F A D_{S}^{2 / 3} w^{1 / 2} v^{-1 / 6} C_{S}}
$$

where $D_{F}$ is the diffusion coefficient of the electroactive species $\left(\mathrm{cm}^{2} \mathrm{~s}^{-1}\right)$ in the film, $P$ is the partition coefficient of the electroactive species between solution and film, $D_{S}$ is the diffusion coefficient of the electroactive species $\left(\mathrm{cm}^{2} \mathrm{~s}^{-1}\right)$ in solution, $d$ is the film thickness and the other symbols have the meaning referred earlier. Eq. (2) reduces to equation 1 when the first right-hand term is negligible, which occurs under at least one of the following conditions: thin films, large value of $P$ or large value of $D_{F}$. For thicker films, or lower diffusion coefficient in the film, Levich plot is not linear, but a plot of $i_{l e v}{ }^{-1}$ vs. $w^{-1 / 2}$ (inverse Levich plot or Koutecký-Levich plot [20]) should be linear.

If permeation is made through pinholes (Fig. 4b), two different models of diffusion have to be considered at the interface film/solution: linear and radial diffusion. In these conditions, the limiting current $i_{\ell}$ is described by equation 3 [20]:

$$
\frac{1}{i_{\ell}}=\frac{1}{n F A D_{F} P C_{S} / d}+\frac{1}{F \frac{R_{a}}{0.6 R_{0}^{2}} D_{S} C_{S}}+\frac{1}{0.620 n F A D_{S}^{2 / 3} w^{1 / 2} v^{-1 / 6} C_{S}}
$$

where $R_{a}$ is the average pinhole radius, $R_{0}$ is half of the distance between the centres of two neighbour pinholes and the other symbols have the already referred meaning.

Savéant [20] pointed out that this equation allows treating permeation through pinholes as membrane permeation, with different diffusion coefficients. The difference between the two models is that the polyelectrolyte film is regarded as blocking electron transfer in pinhole model and not in the membrane model. In fact, in the former model, electron transfer can just occur in non-modified places of the gold disk electrode (film defects). In contrast, in the membrane model, electron transfer can occur at whole electrode surface, being ruled by a smaller diffusion than in bare electrode [20]. 


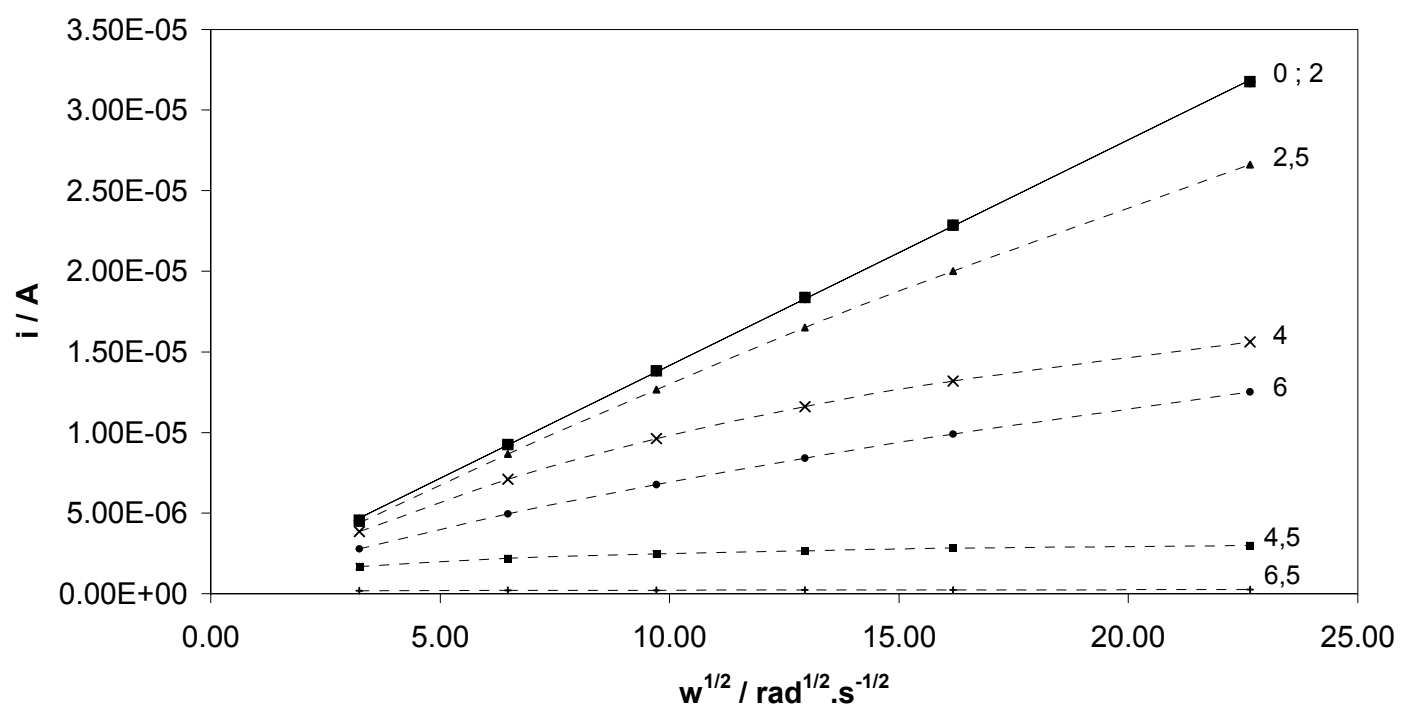

Figure 5. Levich plots of film modified rotating disk electrodes referred in Fig. 3, using several rotation rates, in the same experimental conditions (sweep rate: $10 \mathrm{mV} \mathrm{s}^{-1}$ ). The numbers indicate the $\mathrm{n}$ value in $\mathrm{Au}+$ cysteamine $+(\mathrm{PSS}+\mathrm{PAH})_{\mathrm{n}}$.

Fig. 5 shows Levich plots obtained for bare and film modified electrodes. Linear Levich plots are obtained only up to four layers, indicating that this film is not compact. For higher number of layers Levich plots are not linear but, in contrast, inverse plots were found to be linear (Fig. 6), indicating an important contribution of more thick films in the permeation of the electroactive species.

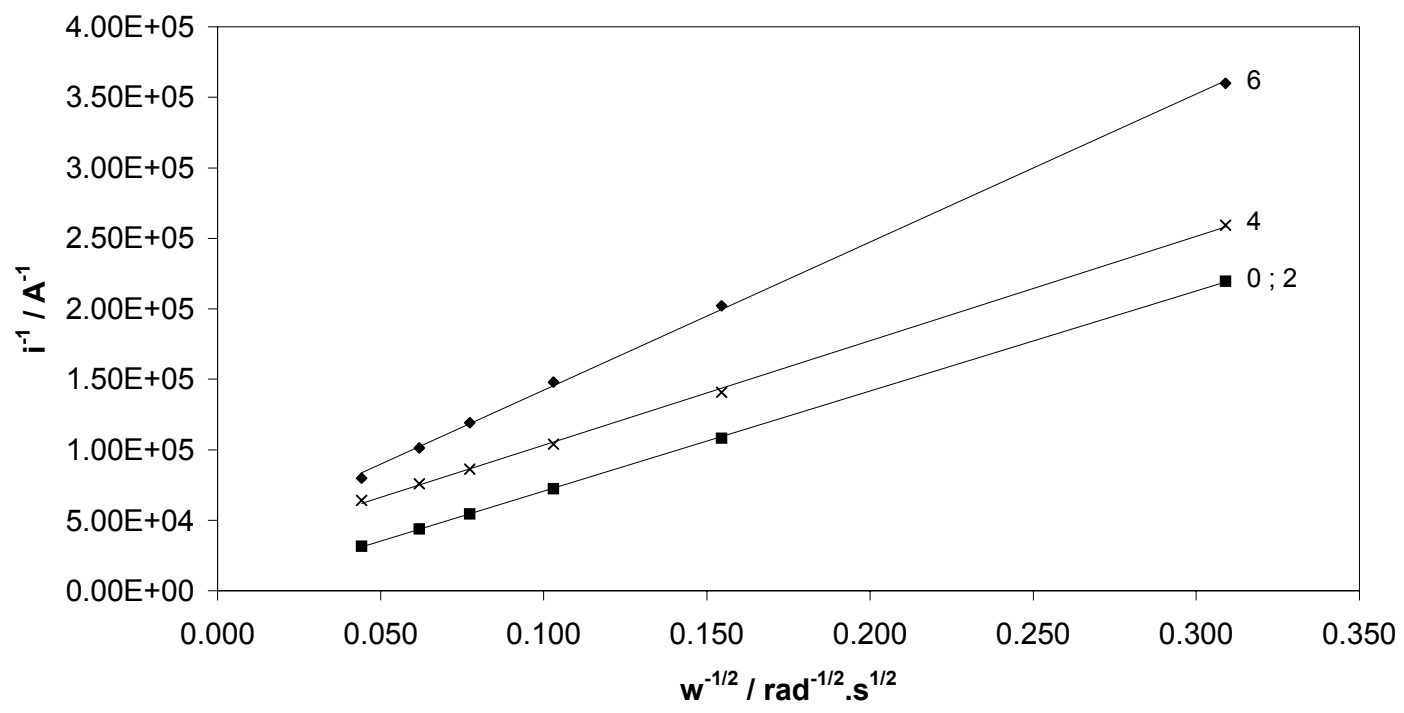

Figure 6. Reversed Levich plots of film modified rotating disk electrodes referred in Fig. 3, using several rotation rates, in the same experimental conditions (sweep rate: 10 $\left.\mathrm{mV} \mathrm{s}^{-1}\right)$. The numbers indicate the $\mathrm{n}$ value in $\mathrm{Au}+$ cysteamine $+(\mathrm{PSS}+\mathrm{PAH})_{\mathrm{n}}$. 
Analysing the results obtained, both phenomena seem to be present: there is a shift in potential and a smaller limiting current, which means that both permeation types may be present in this kind of modified electrodes, with a transition from linear to radial diffusion, as the number of deposited layers increases above certain limit.

\section{Conclusions}

The permeability of polyelectrolyte films is non-linearly lowered with the increasing number of layers, which may result from the increase in thickness of a barrier (resistance) to the electron transfer. The increasing number of layers seems to change also the diffusion process, from linear to radial, with the polyelectrolyte film being compared to an array of microelectrodes.

The charge of the outermost layer have an important role in film permeability, more evident in thicker films: when a layer is added to a film and the outermost layer charge is changed in such a way that it has the same signal as the electroactive species, the permeability is even more lowered that would be only by the effect of increasing film thickness.

Experiments using electrodes with different layer numbers are being performed,

aiming to better understand these phenomena. The effect of ionic force and $\mathrm{pH}$ in film permeability is also being studied.

\section{Acknowledgements}

Tiago H. Silva and S. Barreira gratefully acknowledge Fundação para a Ciência e a Tecnologia for Ph.D. grants.

\section{References}

1. G. Decher, Science 277 (1997) 1232-1237.

2. L.G. Paterno, L.H.C. Mattoso, O.N. Oliveira Jr., Química Nova 24 (2001) 228-235.

3. S.T. Dubas, J.B. Schlenoff, Macromolecules 32 (1999) 8153-8160.

4. S.T. Dubas, J.B. Schlenoff, Macromolecules 34 (2001) 3736-3740. 
5. F. Caruso, K. Niikura, D.N. Furlong, Y. Okahata, Langmuir 13 (1997) 34223426.

6. J.J. Harris, J.L. Stair, M.L. Bruening, Chem. Mater. 12 (2000) 1941-1946.

7. S.-H. Lee, J. Kumar, S.K. Tripathy, Langmuir 16 (2000) 10482-10489.

8. D. Laurent, J.B. Schlenoff, Langmuir 13 (1997) 1552-1557.

9. G. Ladam, P. Schaaf, F.J.G. Cuisinier, G. Decher, J.-C. Voegel, Langmuir 17 (2001) 878-882.

10. F. Caruso, K. Niikura, D.N. Furlong, Y. Okahata, Langmuir 13 (1997) 34273433.

11.J.G. Franchina, W.M. Lackowski, D.L. Dermody, R.M. Crooks, D.E. Bergbreiter, K. Sirkar, R.J. Russell, M.V. Pishko, Anal. Chem. 71 (1999) 3133-3139.

12. F. Caruso, D.N. Furlong, K. Ariga, I. Ichinose, T. Kunitake, Langmuir 14 (1998) 4559-4565.

13. A.V. Nabok, F. Davis, A.K. Hassan, A.K. Ray, R. Majeed, Z. Ghassemlooy, Mat. Sci. Eng. C 8-9 (1999) 123-126.

14. V.P. Yissar, E. Katz, O. Lioubashevski, I. Willner, Langmuir 17 (2001) 11101118 .

15. J.J. Harris, M.L. Bruening, Langmuir 16 (2000) 2006-2013.

16. S. Han, B. Lindholm-Sethson, Electrochimica Acta 45 (1999) 845-853.

17. A.J. Bard, L.R. Falkner, Electrochemical Methods, $2^{\text {nd }}$ ed., Wiley, New York, 2001, chapter 8 .

18. T.R. Farhat, J.B. Schlenoff, Langmuir 17 (2001) 1184-1192.

19. A.M.O. Brett, C.M.A. Brett, Electroquímica. Princípios, Métodos e Aplicações, Almedina, Coimbra, 1996, chapter 8.

20. J.-M. Savéant, J. Electroanal. Chem. 302 (1991) 91-101.

21. T. Ikeda, P. Denisevich, K. Willman, R.W. Murray, J. Am. Chem. Soc. 104 (1982) 2683-2691. 